one need not doubt for a minute that it is perfectly safe in the hands of an expert anæsthetist.

3. The operator would appreciate this method, as it gives him longer time to do the work in hand thoroughly. E tch extraction being performed deliberately, would be a great advantage to -

4. The patient, inasmuch that it would mean less damage to the alveolar process, and thus a quicker healing and absorption of the tooth sockets.

5 . The instantaneous action of the oxygen in arresting accelerated breathing.

II. Its advantage over ether, ethyl ohlorude, and ohloroform. -1 . It is a safer anæsthetic. 2. It requires no special preparation of the patient. 3. The patient's recovery is much quicker, and is, as a rule, unattended by any unpleasant after-effects, as vomiting, headache, \&c., the patient being quite able to go home after a few minutes.

\section{Advantages of the Apparatus.}

1. The extreme simplicity and ease in learning how to manage it. The anrsthetist practically has the whole control of the inhaler and the patient, in the small handle of the regulator.

2. Only one hand is necessary to hold the entire inhaler in positi in (i e., hoth nose-piece and mouth-piece together), leaving the other hand tree to manipulate the gag, \&c.

3. "The same movement of the regulator cuts the "gas" nff and simultaneously admits air, which enters immediately beion the patient's nostrals.

4. There is no need to remove the nose-piece from the patient's face to admit air, this being a great advantage to the operator. Its shape, also, is such that it is well out of the operator's way.

5. The Naso-Oral Inhaler will fit practically everybody.

6 . The nose-piece is so made that it takes up the minimum amount of space, and at the same time has the maximum size for its apertures.

7. The oxygen is quite independent of the $\mathrm{N}_{2} \mathrm{O}$.

8. The quantity of oxygen used is always visible.

9. Great economy of oxvgen.

10. Great economy of $\mathrm{N}_{2} \mathrm{O}$ if a regulator is used.

11. Definite proportions of air, $\mathrm{N}_{2} \mathrm{O}$, and oxygen can be admitted, if required, by decreasing the pressure of the $\mathrm{N}_{2} \mathrm{O}$ and the oxygen, and moving the regulator on the nose-piece to any desired point between positions 1 and 2 .

12. Both nose-piece and mouth-piece are supplied with expiratory valves.

13. The apparatus can easily be adjusted to any gas-bag, gasometer, regulator, or stop-cock that the dental surgeon may already have in his possession.

This apparatus has had a successful trial at Guy's Hospital Dental Oat-patient Department during the summer term and lony vacation, and has been approved by the dental surgeons and anæsthetists present.

The following can be cited as examples of two of the cases, which we had during the winter session :-

CASE 1.-One Saturday morning (Oct. 22nd, 1910) Mr. Marmaduke Page easily maintained anæsthesia with this apparatus for a period of about seven or eight minutes, though, unfortunately, no exact time was recorded. During anæsthesia, Mr. MI sntagu Hopson removed a myeloid epulis from an upper jaw, and at the same time extracted the adjoining right central incisor. Both sides of the alveolar process were thoroughly scraped and then cauterised with pure carbolic acid. After this, the incisor was replanted, being kept in place by a special dental splint made of metal, which was cemented over the teeth with copper oxy-phosphate. The splint was held firmly in position while the cement set. anæsthesia being maintained during the whole process. The patient, a girl, aged 13 years, had a quick recovery, with no unpleasant after-effects, and was able to walk home almost immediately.

CASE 2.-A similar nperation tonk place on Saturday, Nov 19r, 1910, when Mr Montagu Hopson again removed a myeluid sarcoma, with extraction and replantation of the adjoining lateral incisor. In this case anæsthesia was maintained for 10 minutes 25 scomds-i.e., until the completion of the operation. A longer anæsthesia was required on this occasion, owing to the fact that the dental pulp was removed and the nerve canal carefully filled with an antiseptic material prior to the replantation of the incisor. A special dental splint was then applied as before. The patient (female, aged 22 years) had a similar recovery as that mentioned in Case 1 , which was excellent in every way. It should be remarked that she was distinctly a very neurotic patient, and a pronounced mouth-breather. The third position of the regulator on the nose-piece proved of great value.

I should like to acknowledge that the appearance of this apparatus is largely due to the excellent instruction and practice that $I$ was fortunate enough in obtaining from the staff anæsthetist who taught me. If, by chance, he should read this article he will see that I fully appreciate the 12 months' course of instruction that he gave me, and the splendid practice I had in administering general anæsthetics as his "full clerk" in the surgical and dental out-patient department.

I am grateful also to the dental surgeons, assistant dental surgeons, and anæsthetists, for their courtesy and kindness in allowing me to use the inbaler in the out-patient department at Guy's Hospital.

Acknowledgments are due to the Dental Manufacturing Company, of Newman-street, Oxford-street, W., for their willingness in making the apparatus for me, for their belp in assisting me in getting out a universal shaped nose-piece, and for their patience in making many slight alterations to perfect the same.

In conclusion, I wish to thank Mr. Kenneth Hoby, L.D.S. Eng., and Mr. Ellison, co-manager of the company, for help as regards the drawings and woodcut.

Bruckley-road, S.E.

\section{Clinital oflotes:}

MEDICAL, SURGICAL, OBSTETRICAL, AND THERAPEUTICAL.

\section{THE ADMINISTRATION OF THYROID GLAND SUB- STANOE UPON SERUM RASH AND SERUM SICKNESS IN DIPHTHERIA.}

By A. E. Hodgson, M.B. Edin., D.P.H. Camb., RESIDENT MEDICAL OFFICER, CITY HOSPITAL EAST, LIVERPOOL.

THE occurrence of serum rashes, either alone or in conjunction with high temperature, arthritic pains, œdema, inflamed throat, adenitis, rhinitis, albuminuria, \&c., forming the syndrome designated by vin Pirquet as "serum disease," after the hypodermic injection of diphtheria antitoxin and other sera, and the graver anaphylactic complications, have attracted very considerable attention during recent years, both at home and abroad.

The conclusions most generally accepted are: (1) That the phenomena are not due to any substance in. the antitoxic elements of the serum, but to a protein body inherent in the serum itself ; (2) that serum rash and serum sickness or disease may follow one injection only, but will follow more rapidly when a second injection is made, coming on earlier as a rule, the more recent the first injection; and (3) that anaphrlaxis usually only becomes a possibility when a second injection is made from 10 to 12 dass and onwards, after the primary one.

Simple serum rash may be of no consequence in a case of diphtheria, in so far as bad results are concerned. On not a few occasions however, I have seen infants rendered dis. tinctiy " croupy " by cedema of portions of the air passages, coincident with, or resultant upon, an urticarial serum rash. Serum sickness, when severe, may very considerably tax a patient whose system is already burdened with the toxins of diphtheris; and I cannot agree with a recent writer in whose opinin the occurrence of a sharp febrile reaction has been rather useful than otherwise in very prostrate patients. The pvrexia, amounting to $103^{\circ} \mathrm{F}$., or even $1 \mathrm{C} 4^{\circ}$ in some cases which I have observed, cannot but have some detrimental effect upon the cardiac muscle. Similarly, the sudden odemas are commonly accompanied by an alarming fall in blnod tension. Two cuses in mp recollection-each suffering from only a comparatively mild attack of diphtheria-came to a fatal issue as a result of exhaustion following a severe attack of serum sickness. The condition of anaphylaxis, I have fortunately not encountered as yet. 
The conclusions referred to earlier undoubtedly include certain main factors involved in the causation of these conditions; but that other elements enter into the etiology is also admissible. Olinical experience proves that one particular series or batch of serum (probably from a particular horse), will cause a higher percentage of undesirable sequelæ than another series; and may there not be other factors inherent in, or peculiar to, the patient himself?

In a paper entitled, "Serum Sickness and Sudden Death following the Hypodermic Administration of Antitoxin," by Dr. Miller and Dr. Root of Detroit, published in the Therapeutio Gazette for February, 1910, the writers discuss this point, and in their conclusions suggest the possibility of a relationship between serum sickness and sudden death and "status 1ymphaticus or some allied condition"; or, in other words, that these particular antitoxin sequelæ may bear some connexion with a greater or less degree of a "hyperlymphatic" state, if I may coin such an expression.

Following up this idea, with particular regard to serum sickness, and with a view of counteracting any tendency to this hyper-lymphatic or hyper-thymic state, a number of cases of diphtheria were given thyroid gland substance in the form of thyroid gland tablets (Parke, Davis, and Co.), simultaneously with, and for some days following, the administration of antitoxin. The dosage employed was, roughly, as follows: Up to 5 years, $1 \frac{1}{4}$ grains daily, for six doses (decreased in infants); from 5 to 10 years, $2 \frac{1}{2}$ grains daily, for six doses ; from 10 to 15 years and upwards, 5 grains on alternate days, for four doses: In all, 100 cases were observed, 50 receiving thyroid and 50 receiving none, the latter acting as control cases. The antitoxin employed was, in all cases, taken from a serum series which was clinically known to produce a large incidence of rashes, \&c. My results may be tabulated thus :-

\begin{tabular}{|c|c|c|c|c|c|c|}
\hline \multirow[b]{2}{*}{ Total number observed } & \multicolumn{4}{|c|}{$\begin{array}{c}\text { Cases receiving } \\
\text { thyroid. }\end{array}$} & \multicolumn{2}{|c|}{$\begin{array}{l}\text { Cases not re- } \\
\text { ceiving thyroid. }\end{array}$} \\
\hline & & & 50 & & ......., & 50 \\
\hline No sequelæ... ... ... & $\ldots$ & ... & 29 & & ......... & 22 \\
\hline Simple $\operatorname{rash} . . . .$. & $\ldots$ & $\ldots$ & 15 & & .......... & $1 ?$ \\
\hline Serum sickness ... ... & $\cdots$ & $\cdots$ & 6 & ..... & ................. & 16 \\
\hline
\end{tabular}

The figures of the first and second sections are not particularly striking, but the large number of cases in the non-thyroid column which suffered from serum sickness, and the small number in the thyroid column, at least suggest that the thyroid gland substance has some effect in modifying the condition.

The number of cases under observation, however, is not sufficiently large to admit of the drawing of anything in the shape of a definite conclusion; nevertheless, the results may be of sufficient interest to stimulate further observations in this subject.

Liverpool.

\section{AUTO-INOCULATION AND MASSAGE IN A CASE OF GONORRHCEAL SYNOVIIIS.}

Bx J. R. RIGden Trist, M.R.O.S. Eng., L.R.C.P. Lond.

THE patient in this case, a man, aged 26 years, was under my care four years ago suffering from gonorrhoea. There was considerable fever, and for a fortnight he was very ill ; there was als: a severe conjunctivitis. He was kept in bed and thorough irrigation with argyrol was followed by complete recovery of the eyes. The urethra having been washed out with argyrol, he began to improve, and by the end of a month was fairly happy and comfortable and taking bis food well, and the temperature had begun to settle. He then had pain in his right knee and the temperature went up to over $100^{\circ} \mathrm{F}$. There was a gonorrboal synovitis. Immobilisation and fomentation of the affected knee with continuance of active measures to the urethra were followed by a commencing fall of temperature in about a week, and at the end of a fortnight I ordered massave once to the affected $j$ int. taking care that the temperature was observed. Within 12 hours the temperature was over $100^{\circ}$. I interpreted this as evidence that the massage had produced a condition of auto-inoculation. waited tor the temperature to settle down again, as it did in less than a week, and repeated the ma-sage; a similar but less pronounced reaction ensued. The treatment was repeated, the temperature chart being used as a guide, and it was found that longer massage was needed before the reaction was observed. Massage was continued periodically on this plan until no reaction took place, and the patient left the nursing home apparently cured at the end of about eight weeks.

I should not, I think, adopt this method again in the treatment of gonorrhoea because I should use a gonococcus vaccine, but I have thought that the case is instruciive as bearing on the subject of auto-inoculation sn ably dealt with in Dr. Clive Rivière's thoughtfal paper in THE LANCET of Jan. 28th.

Auto-inoculation is, I take it, an important factor in the good results obtained by massare in acute osteo-arthritis, a condition in which the preparation of a vaccine is not always possible owing to the difficulty of determining the organism or organisms responsible for the lesions.

Putney Bridge-road, s.W.

\section{Mtedical Sorieties.}

\section{ROYAL SOCIETY OF MEDICINE.}

\section{SECTION FOR THE STUDY OF DISEASE IN CHILDREN.}

Exhibition of Cases and Specimens. - Splenomegaly.-Ulcerative Stomatitis in Children.

A MeEting of this section was held on Jan. 27th, Dr. E. CAUTLEY, the President, being in the chair.

Dr. ERIC Pritchard showed: 1. Intermittent Wordblindness (Congenital) in a boy, aged $8 \frac{1}{2}$ years, who was both intelligent and dexterous. His vision was normal and his hearing good. He was slow at learning to read, but quick at mental arithmetic, and had no difficulty in reading Arabic numerals. He could recognise simple words when spelt aloud, but as a rule was quite unable to recognise the same words when written. On occasions, however, he could read simple sentences. He could write from dictation and copy written words, but did not understand their meaning unless he repeated the letters slowly, or slowly performed the movements for writing them. Thus, though his visual memories for words and letters were defective, his auditory and kinæsthetic memories were good. The intermittent character of the word-blindness was suggestive that the condition was a psychosis rather than due to a defect in the visual word centre. 2 Idioglossia in a girl, aged $9 \frac{1}{2}$ years. The child was prematurely born, and her mother's half brother was a deaf-mute. She was two years old before her speech was intelligible. She was a bright child, who wrote and composed well. Her mental condition was normal, but her hearing was slightly defective. The vowel sounds were more or less correctly pronounced, but consonants presented a difficulty, C, D, T, G being all pronounced Nee, $\mathrm{H}$ as Hay, $\mathrm{J}$ as Nai, $\mathrm{S}$ and $\mathrm{X}$ as $\mathrm{Ai}, \mathrm{V}$ as $\mathrm{Mew}, \mathrm{Z}$ as Ney, \&o.

Mr. H. S. ClOGG exhibited a specimen from the case of Necrosis of the Lower Jaw, shown at the last meeting. The child subsequently had abscesses on either side of the jaw, which were incised, and it was determined to remove the necrosed portion of the bone. The specimen consisted of the whole of the lower jaw except the inner shell of the ascending ramus and the condyloid process on the left side. In the place of the jaw the child now had a firm, solid arch, but whether this was bone or not it was impossible to say.

Dr. T. R. C. WhIPHAM showed a case of Enlargement of the Liver in a healthy-looking boy, aged 9 years, with no symptoms except slight jaundice. The liver was enormous, reaching down to the anterior superior spine of the ilium and to the umbilicus in the middle line and extending below the left costal margin. In the epigastric angle was a large round swelling, which appeared to rise from the surface of the liver and was more elastic than the rest of the organ. The spleen at one time had been just palpable below the ribs. There was no ascites and the chest was normal. There was no enlargement of glands anywhere. The blood showed an eosinophilia of 78 per cent. but no other marked changes. The boy presented no external signs of congenital syphilis, but there was a history of the mother having had three miscarriages. During the past five weeks no change had 